\title{
The Features of Interaction of Combustion Front with Flat Obstacles by the Example of the Flames of Methane-Oxygen Mixes
}

\author{
N.M. Rubtsov ${ }^{1}$, A.P. Kalinin ${ }^{2}$, G.I. Tsvetkov ${ }^{1}$ and K.Ya. Troshin ${ }^{3}$ \\ ${ }^{1}$ Institute of Structural Makrokinetics and Materials Science, Russian Academy of Sciences, \\ Moscow region, Chernogolovka, 142432, Russia \\ ${ }^{2}$ A.Yu. Ishlinsky Institute for Problems in Mechanics, Russian Academy of Sciences, \\ Moscow, 119526, Russia \\ ${ }^{3}$ N.N. Semenov Institute of Chemical Physics, Russian Academy of Sciences, \\ Moscow, 119991, Russia \\ nmrubtss@mail.ru
}

\begin{abstract}
It was shown that maximum pressure and maximum acoustic intensity are much greater for the obstacle with several openings as compared with the obstacle with single opening. It was shown that both minimum pressure of flame penetration and minimum diameter of an opening, through which the flame of the diluted methane-oxygen mix can penetrate decrease with an increase in the number of openings. Numerical calculations based on low Mach number approximation of the compressible reactive Navier-Stokes equations showed good qualitative agreement with experimental results. It was concluded that at assessment of a fire safety of the room or confinement with several openings one should not use the value of the minimum size of the single opening, because at an increase in the number of openings the size sufficient for flame penetration decreases.
\end{abstract}

Keywords: high-speed cinematography, flame propagation, turbulence, gasdynamic and kinetic features, methane-oxygen mixture, obstacle, opening, limiting conditions.

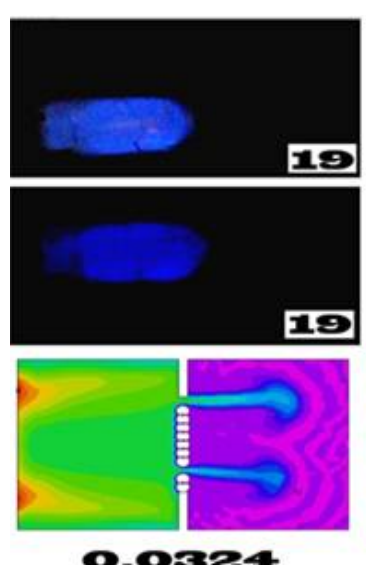

0.0824
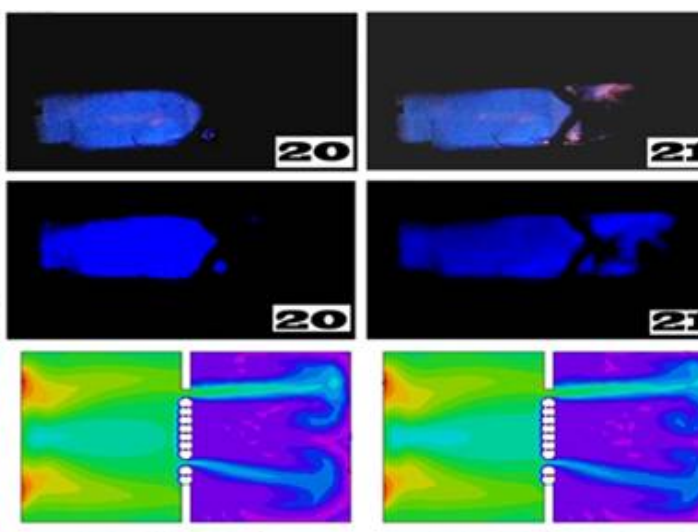

O.oegi

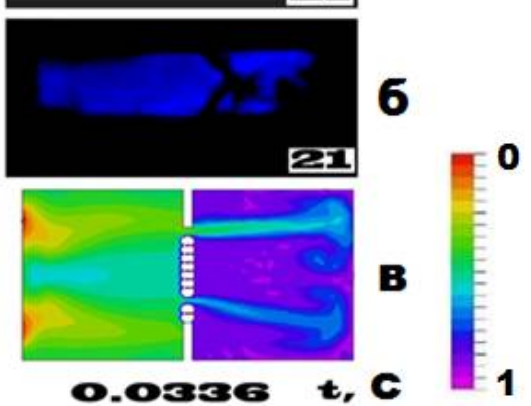

Speed filming of flame front penetration through

a) a flat obstacle $14 \mathrm{~cm}$ in diameter with two asymmetrical openings $15 \mathrm{~mm}$ in diameter on the axis (the first one is located $35 \mathrm{~mm}$ from the center, the second one $-55 \mathrm{~mm}$ from the center);

b) the same obstacle interference filter $435 \mathrm{~nm}$ is placed in front of the camera. Initial pressure 155 Torr. The frame number on all figures is the frame number after initiation. 600 frames/s in all figures; c) results of numerical calculation of the process of flame penetration through the obstacle: dimensionless concentration of initial substance for $n=0$ on the obstacle (first type of boundary conditions). On the bottom to the right is dimensionless concentration of initial substance. 


\title{
Особенности взаимодействия фронта горения с плоскими препятствиями на примере пламён разбавленных метано-кислородных смесей
}

\author{
Н.М. Рубцов ${ }^{1}$, А.П. Калинин ${ }^{2}$, Г.И. Цветков ${ }^{1}$, К.Я. Трошин ${ }^{3}$ \\ ${ }^{1}$ Институт Структурной Макрокинетики и Проблем Материаловедения РАН, \\ Россия, Московская область, г. Черноголовка, 142432, Институтская ул., 8 \\ ${ }^{2}$ Институт проблем механики им. А.Ю. Иилинского, Российской академии наук, \\ Россия, Москва, 119526, проспект Вернадского, 101 \\ ${ }^{3}$ Институт химической физики им. Н.Н.Семенова РАН, \\ Россия, Москва, 119991, ул. Косыгина, 4 \\ nmrubtss@mail.ru
}

\begin{abstract}
Аннотация
Экспериментально установлено, что максимальное давление и максимальная акустическая интенсивность намного больше для препятствий с двумя и тремя отверстиями, чем с одним центральным отверстием. Установлено, что как минимальное давление проникновения пламени так и минимальный диаметр отверстия, через которое может проникнуть пламя разбавленной метано-кислородной смеси при начальных давлениях до 200 Торр, уменьшаются с увеличением количества отверстий. Расчёты, проведённые на основе уравнений Навье-Стокса для сжимаемой реагирующей среды в приближении малого числа Маха показали хорошее качественное согласие с результатами экспериментов. Приведённые результаты позволяют прийти к выводу, что при оценке пожарной безопасности помещения с несколькими отверстиями величину минимального размера единственного отверстия использовать не следует, потому что при увеличении количества отверстий размер отверстия, достаточный для проникновения пламени, уменьшается.

Ключевые слова: скоростная киносъемка, распространение пламени, турбулентность. газодинамические и кинетические особенности, метано-кислородная смесь, препятствия, отверстия
\end{abstract}

\section{1. Введение}

Влияние различных препятствий, расположенных в объемах, заполненных горючей смесью, на распространении фронта пламени (ФП), исследуется в течение долгого времени $[1,2]$. Известно, что, если состав газовой смеси далек от пределов воспламенения, то скорость фронта пламени в присутствии препятствий может увеличиться до сверхзвуковой [3, 4]. Актуальность исследования ускорения пламен обусловлена преимущественно проблемами взрывобезопасности [5]. В нештатной ситуации определенное количество легковоспламеняющегося газа может быть выпущено в атмосферный воздух. Получающаяся взрывчатая смесь подвергает опасности целостность судна, реактора, шахты и т.д. Сила взрыва зависит от формы объема, в котором заключена горючая смесь, и количества отверстий в нем, а именно, дверей, окон и вентиляционных проёмов. Хотя многое важные характеристики ускорения пламени были исследованы различными авторами [1-6], объём данных, полученных методами высокого временного разрешения для процесса в целом, а не в некоторой локальной области 
пространства, ещё не достаточно велик. Очевидно, что такие данные очень важны как для решения проблем взрывобезопасности, так и для апробации вычислительных программ, моделирующих подобные нештатные ситуации. В соответствии с понятием предела распространения пламени по диаметру единственного отверстия в препятствии, существует некоторое критическое значение диаметра отверстия; при меньшем диаметре пламя через отверстие не проникает. Вместе с тем ранее было показано, что разбавленное пламя метана с кислородом проходит через мелкие сетки, т.е. через препятствия, состоящие из большого количества отверстий весьма малого диаметра [6]. Это означает, что количество отверстий в препятствии влияет на предел проникновения пламени через препятствие.

Этот вопрос, который непосредственно относится к взрывобезопасности, по существу не рассмотрен в литературе.

В работах [6, 7] экспериментально показано, что при проникновении ФП через препятствия, газодинамические факторы, например, турбулизация пламени, находятся в тесной взаимосвязи с кинетикой горения. В работе [7] было установлено, что возникновение ФП после одиночного препятствия не происходит в непосредственной близости от препятствия, первичный очаг воспламенения наблюдается на некотором расстоянии от поверхности препятствия (“скачок пламени”). Было показано, что использование сеточной сферы в качестве препятствия приводит к росту длины “скачка” пламени позади препятствия по сравнению с круглым отверстием. Показано, что два или больше препятствия как сферической, так и плоской формы, существенно подавляют распространение ФП. Показано, что длина "скачка пламени" после отверстия в препятствии определяется временем перехода от ламинарного к турбулентному течению газа, а не временем задержки воспламенения. Установлено, что при проникновении пламени через препятствия газодинамические факторы, такие как турбулизация пламени, могут определить кинетические особенности горения, в частности, переход режима низкотемпературного горения углеводородов к высокотемпературному режиму [8].

Из-за сложностей, связанных с газодинамикой, определяемой геометрией камер сгорания, и особенно со сложным кинетическим механизмом разветвленно цепного горения газа, распространение пламени и возникающий разогрев газа не могут быть моделированы с достаточной точностью. Уравнения Навье-Стокса в сжимаемой реагирующей среде могут быть упрощены и использованы для моделирования неизотермического потока, только если использовать приближение малого числа Маха (акустическое приближение) [7-10]. Для низких скоростей турбулентного горения это приближение уравнений Навье-Стокса представляет собой приемлемую основу для моделирования [8,9]. Тем не менее, любое сравнение экспериментально наблюдаемых закономерностей распространения фронта пламени с результатом численного моделирования представляется обоснованным только в качественном аспекте, например, по характеру распространения границы исходного и реагирующего газов, а также по форме этой границы.

Данная работа посвящена установлению влияния количества отверстий в плоском препятствии на минимальный диаметр и минимальное давление проникновения пламени через препятствие.

\section{2. Описание эксперимента}

В работе установлены особенности распространения пламени в стехиометрических смесях метана с кислородом, разбавленных углекислым газом $\mathrm{CO}_{2}$ и аргоном $\mathrm{Ar}$ при начальных давлениях $100 \div 200$ Торр и 298 К в горизонтальном цилиндрическом кварцевом реакторе длиной 70 см и 14 см в диаметре, описанном в [7]. Концы реактора был вакуумно плотно закреплены в двух шлюзах из нержавеющей стали, снабжённых входными отверстиями для напуска и откачки газов и дверцы безопасности, которая открывалась, когда давление газа в реакторе превышало 1 атм [6, 7]. Два электрода инициирования искрового разряда были расположены у левого конца реактора [7]. Тонкие (1 мм) плоские препятствия 140 мм в диаметре с двумя симметрично (в 55 мм от центра) и асимметрично (одно в 35 мм от центра, второе - в 55 мм 
от центра препятствия) расположенными круглыми отверстиями 15 мм в диаметре или тремя круглыми отверстиями 12 мм в диаметре (в 55 мм друг от друга, одно отверстие в центре) помещали вертикально в середину реактора. В нескольких экспериментах препятствие с двумя симметричными отверстиями было оборудовано двумя резервуарами, в которые помещали электровзрывной нанопорошок никеля (60 нм) [11]. Поток газа при распространении пламени слева направо выносил эти частицы из резервуара, и они загорались в пламени. Эти горящие никелевые наночастицы дополнительно визуализировали поток газа во время горения. В некоторых экспериментах использовалось сложное препятствие, состоящее из препятствия с двумя симметричными отверстиями и плоское препятствие с одиночным отверстием 15 мм в диаметре, расположенном в 90 мм от первого препятствия.

Горючую смесь $\left(15.4 \% \mathrm{CH}_{4}+30.8 \% \mathrm{O}_{2}+46 \% \mathrm{CO}^{2}+7.8 \% \mathrm{Ar}\right)$ составляли предварительно; $\mathrm{CO}_{2}$ добавлялся, чтобы увеличить качество съемки за счёт уменьшения скорости ФП; $\mathrm{Ar}$ добавлялся, чтобы уменьшить порог искрового разряда. Реактор заполнялся горючей смесью до необходимого давления. Затем осуществлялся искровой разряд (1.5 Дж).

Скоростная регистрация динамики воспламенения и распространения ФП осуществлялась с боковой стороны реактора с помощью двух скоростных цифровых камер Casio Exilim F1 Pro (частота кадров $600 \mathrm{c}^{-1}$ ) [6, 7]. Одна из камер была снабжена интерференционным фильтром 435 нм (40\% пропускание, полуширина 15 нм), чтобы вырезать излучение $\mathrm{CH}\left(\mathrm{A}^{1} \Delta-\mathrm{X}^{2} \Pi\right)$ при $431 \mathrm{~nm}$ [12]. Видеофайл сохранялся в памяти компьютера. Акустические колебания регистрировались микрофоном Ritmix (до 40 кГц). Аудиофайл хранился в памяти компьютера и анализировался с использованием пакета программ Spectra Plus 5.0. Использовались химически чистые реактивы.

Некоторые особенности проникновения пламени через препятствия были качественно проиллюстрированы методом численного моделирования на основе уравнений Навье-Стокса для сжимаемой реагирующей среды в приближении малого числа Маха $[7,13]$, которые описывают распространение пламени в двумерном канале. Уравнения показали качественное согласие с экспериментами $[6,7,10]$. Решение задачи было выполнено с использованием пакета FlexPDE 6.08, 1996-2008 PDE Solutions Inc. [14]. Использовался простой механизм осуществления реакционной цепи $[6,7]$. Граничные условия (включая отверстие) были

$$
\frac{\mathrm{d} C}{\mathrm{~d} x}=\frac{\mathrm{d} C}{\mathrm{~d} y}=0, \quad u=0, \quad v=0, \quad \frac{\mathrm{d} \rho}{\mathrm{d} x}=\frac{\mathrm{d} \rho}{\mathrm{d} y}=0, \quad \frac{\mathrm{d} T}{\mathrm{~d} t}=T-T_{0},
$$

где $C$ - безразмерная концентрация; $u, v$ - компоненты скорости; $\rho$ - плотность; $T$ - темпеpaтура. $n=0$ (граничное условие первого рода) было принято только на поверхности препятствия. Начальная плотность $\rho_{0}$ и, следовательно, начальное давление $P_{0}$ [6] были выбраны так, чтобы обеспечить отсутствие проникновения пламени через одиночное центральное отверстие той же самой ширины. Задача решалась в прямоугольной области. Условие инициирования $T=10$ на левой границе канала; в середине канала находилось препятствие.

\section{3. Обсуждение результатов}

Ранее был экспериментально определен минимальный диаметр проникновения пламени через препятствие с единственным центральным отверстием, которое в установке составило 20 мм [6], минимальное давление проникновения пламени через это отверстие составило 170 Торр. Отметим, что дверца безопасности не открывалась при этих условиях, т.е. максимальное давление во время горения в реакторе было ниже, чем 1 атм. Эти величины будут использоваться в дальнейшем обсуждении.

Типичные последовательности кадров быстродействующей съемки распространения ФП в горючей смеси при начальном давлении 155 Торр через плоское препятствие 14 см в диаметре с двумя асимметрично расположенными отверстиями 15 мм в диаметре представлены на рис. 1 , а. 

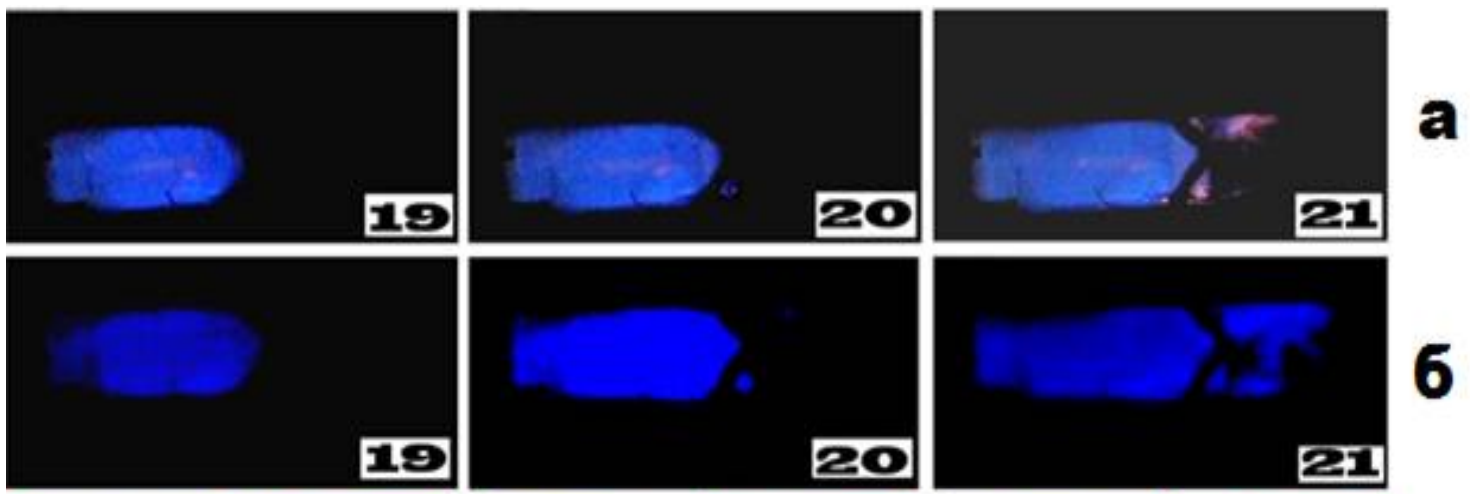

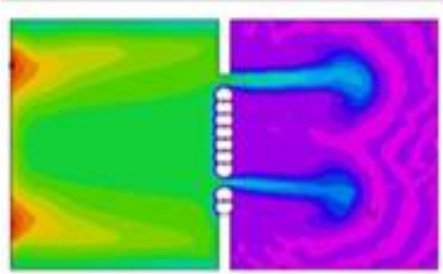

0.0024

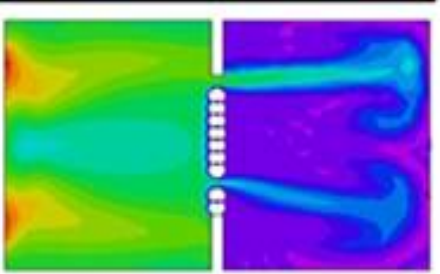

0.0391

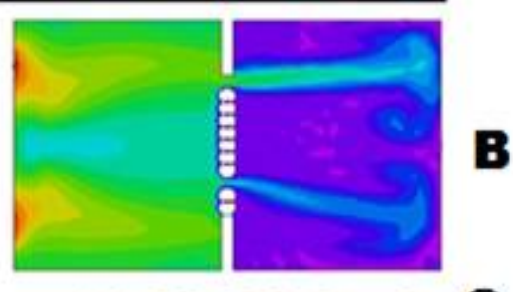

0.0986

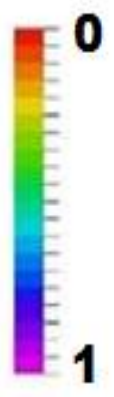

Рис. 1. Скоростная съемка распространения ФП через:

a) плоское препятствие диаметром 14 см с двумя асимметрично расположенными отверстиями на оси диаметром 15 мм (первое - в 35 мм от центра, второе - в 55 мм от центра);

б) то же препятствие, интерференционный фильтр 435 нм помещен перед камерой. Начальное давление 155 Торр. Номер кадра на всех рисунках соответствует порядковому номеру кадра после момента инициирования. Скорость съёмки 600 кадров/с также на всех рисунках;

c) результаты расчёта процесса распространения пламени через препятствие: изменение безразмерной концентрации начального вещества для $n=0$ на препятствии (граничное условие первого рода). Внизу справа - безразмерная концентрация исходного вещества.

Результаты, показанные на рис. 1, б, были получены при использовании интерференционного фильтра 435 нм, который был помещен перед объективом одной из кинокамер, что позволило визуализировать распределение радикалов СН во время распространения пламени. Как видно из рис. 1, б (кадр 20), “скачок пламени” длиннее для отверстия, которое расположено ближе к поверхности реактора. Результат качественного расчёта, приведённый на рис. 1, в, согласуется с этим экспериментальным фактом. Распространение пламени в этих условиях сопровождается характерным звуком, и дверца безопасности открывается. Это означает, что максимальное давление превысило 1 атм. Зависимость акустической интенсивности для плоского препятствия с центральным круглым отверстием при начальном давлении 170 Торр приведена на рис. 2, а. Зависимость для плоского препятствия с двумя асимметричными отверстиями (рис. 1) при начальном давлении 155 Торр приведена на рис. 2, б; видно, что максимальная амплитуда последней зависимости значительно больше.

Типичные последовательности кадров скоростной съемки распространения ФП в горючей смеси при начальном давлении 155 Торр через плоское препятствие диаметром 14 см с двумя симметричными отверстиями диаметром 15 мм, расположенных в 55 мм от центра препятствия, представлены на рис. 3, а. В условиях рис. 3, б интерференционный фильтр 435 нм помещали перед объективом камеры для регистрации распределения возбуждённых радикалов СН во время распространения пламени. Распространение пламени сопровождалось резким звуком, и дверца безопасности открывалась. Таким образом, максимальное давление превысило 1 атм. 


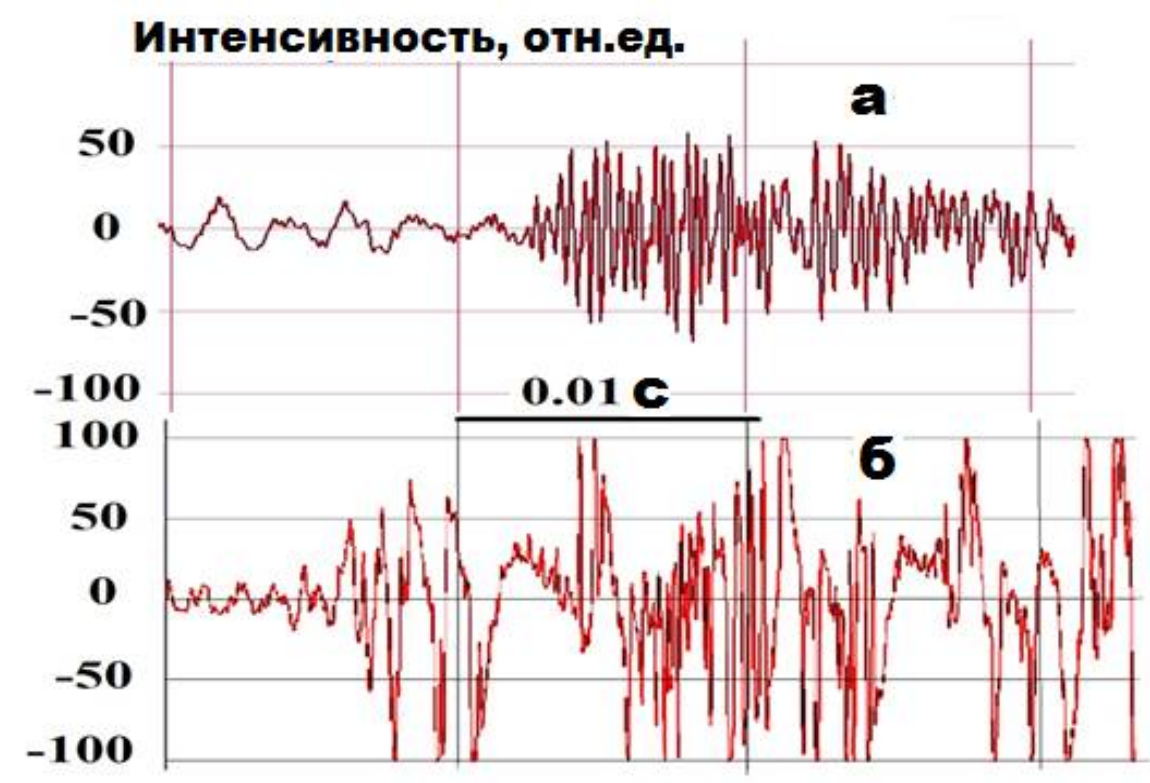

Рис. 2. Зависимость акустической интенсивности от количества отверстий:

a) плоское препятствие с центральным круглым отверстием диаметром 20 мм. Начальное давление 170 Торр;

б) плоское препятствие с двумя асимметричными отверстиями (рис. 1) 155 Торр
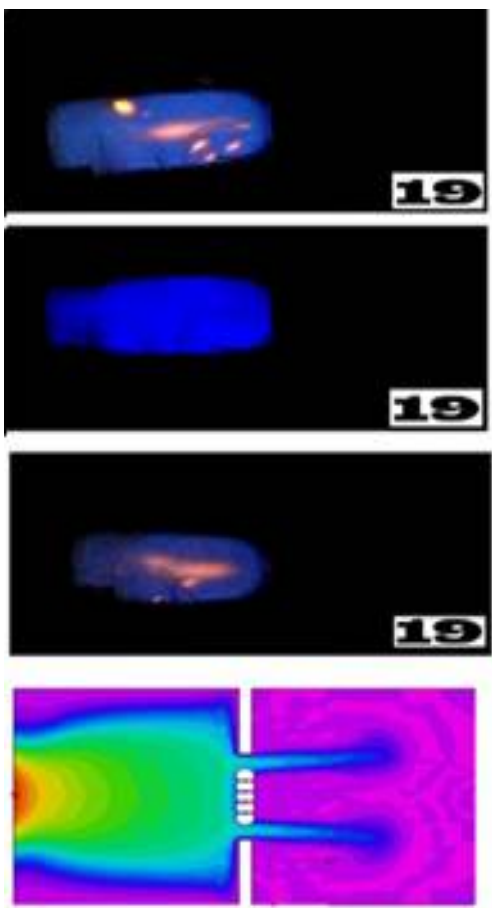

0.082
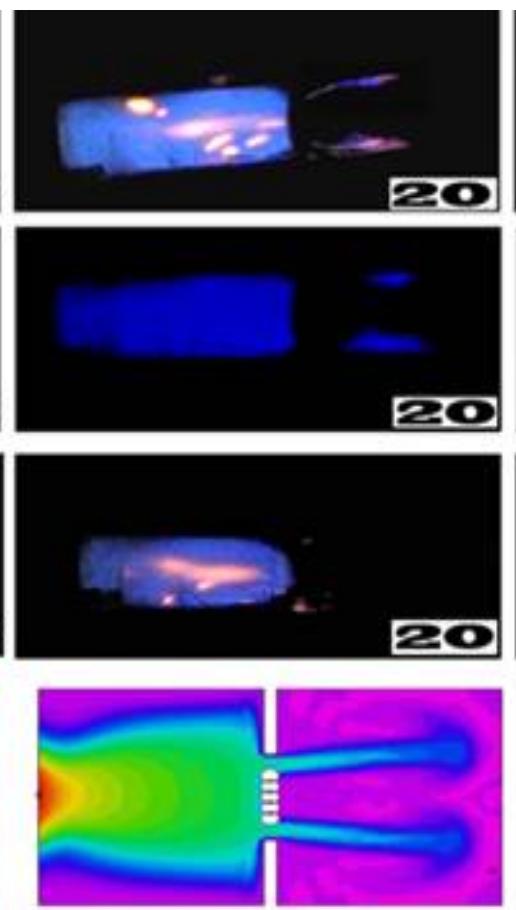

O.oser.

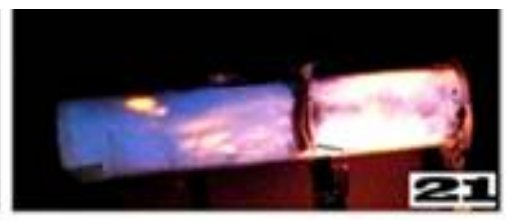

a

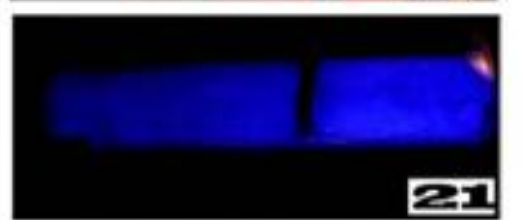

6 .

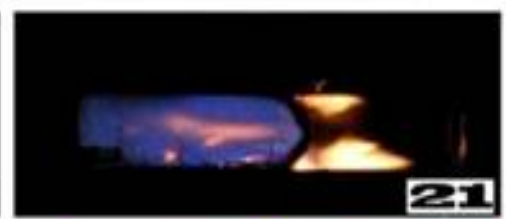

B

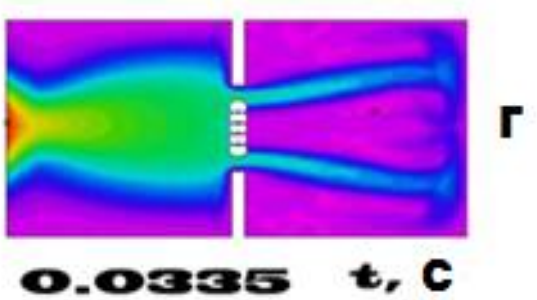

Рис. 3. Скоростная съемка распространения FF через:

a) плоское препятствие диаметром 14 см с двумя симметрично по оси расположенными отверстиями диаметром 15 мм (в 55 мм от центра препятствия);

б) интерференционный фильтр 435 нм помещен перед камерой. Начальное давление 155 Торр;

в) то же препятствие, каждое открытие снабжено резервуаром с нанопорошком никеля;

г) результаты расчёта процесса распространения пламени через препятствие: изменение безразмерной концентрации начального вещества для $n=0$ на препятствии (граничное условие первого рода) 
Последовательности кадров скоростной съемки распространения пламени в горючей смеси при начальном давлении 150 Торр через плоское препятствие диаметром 14 см с тремя отверстиями диаметром 12 мм (расположенные в 55 мм друг от друга на одной линии, одно отверстие находится в центре), представлены на рис. 4, а. На рис. 4, 6 интерференционный фильтр 435 нм помещен перед камерой для регистрации распределения возбуждённых радикалов СН. Распространение пламени также сопровождалось резким звуком, при этом дверца безопасности открылась, т.е. максимальное давление превысило 1 атм. Как видно из рис. 4, а, пламя проникает только через два отверстия; поэтому условия рис. 4, а можно считать предельными этого препятствия.
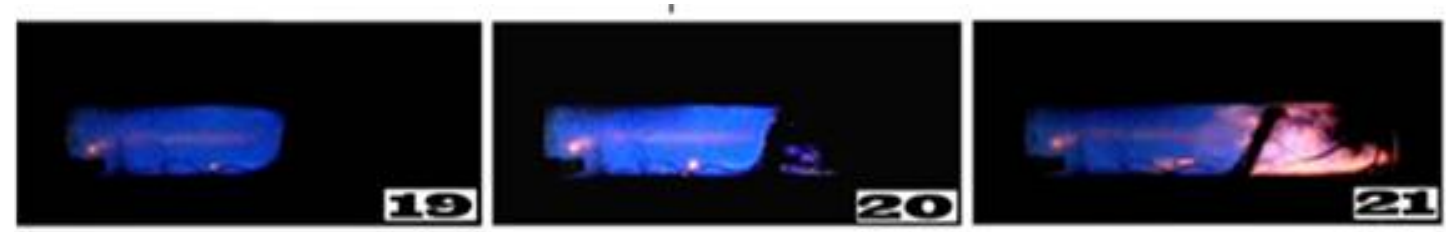

a
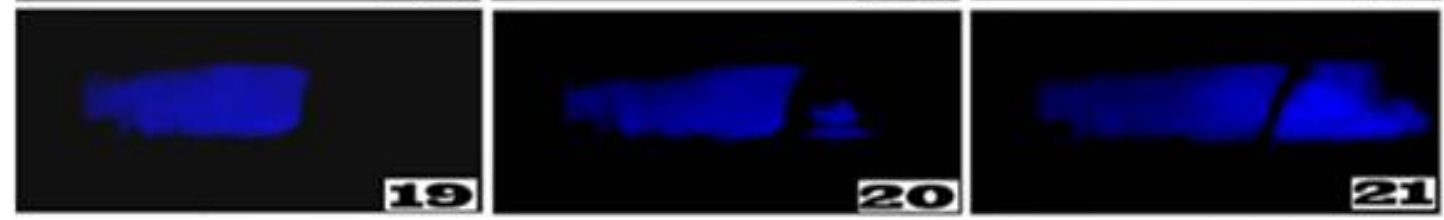

6
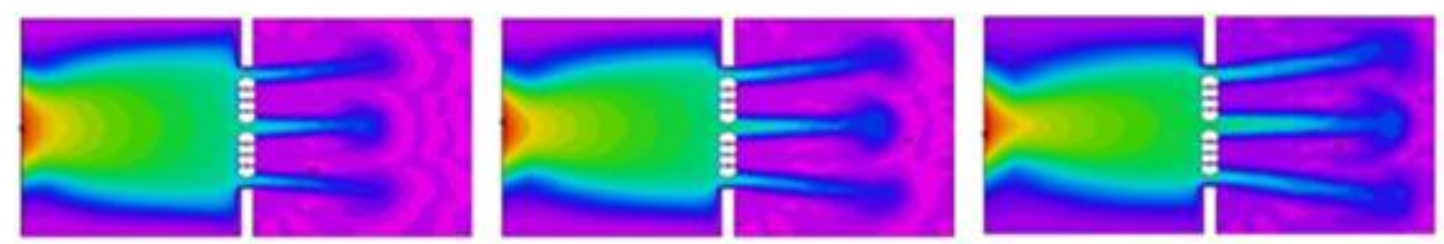

B
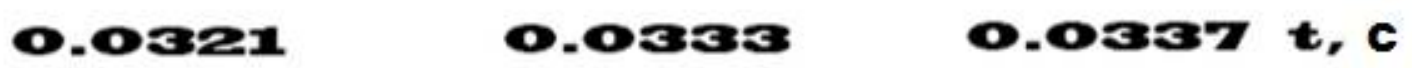

Рис. 4. Скоростная съемка распространения ФП через:

a) плоское препятствие диаметром 14 см с тремя отверстиями диаметром 12 мм, находящимися на оси препятствия в 55 мм друг от друга, одно отверстие находится в центре;

б) то же препятствие, интерференционный фильтр 435 нм помещен перед камерой. Начальное давление 150 Торр;

в) результаты расчёта процесса распространения пламени через препятствие: изменение безразмерной концентрации начального вещества для $n=0$ на препятствии (граничное условие первого рода)

Как можно видеть из рис. 1, 3, 4, диаметры отверстий для препятствий на этих рисунках значительно меньше, чем минимальный диаметр проникновения пламени через препятствие с одиночным центральным отверстием (20 мм, см. выше). Общее давление проникновения пламени через эти препятствия также меньше, чем минимальное общее давление проникновения пламени через одиночное центральное отверстие (170 Торр). Однако максимальное давление и максимальная акустическая интенсивность (см. рис. 2) намного больше для препятствий с двумя и тремя отверстиями. Наблюдаемые закономерности отражают тот факт, что, что два отверстия и тем более три являются более эффективными турбулизаторами, чем одиночное отверстие, при этом предел по диаметру заметно понижается с увеличением числа отверстий. В пользу сказанного свидетельствуют также результаты вычислений процесса проникновения пламени через препятствие (рис. 1, в; 3, в; 4, в), которые качественно согласуются с данными экспериментов, представленными на рис. 1, а, б; 3, a, б; 4, а, б. Напомним, что условия расчётов были выбраны так, что проникновение пламени через одиночное центральное открытия той же самой ширины как на рис. 1, в не имело места. 
На рис. 5, а представлены типичные последовательности кадров проникновения пламени через сложное препятствие, содержащее плоское препятствие диаметром 14 см с двумя симметрично расположенными отверстиями диаметром 15 мм (как на рис.2) и второе плоское препятствие с единственным отверстием диаметром 15 мм, расположенным в 90 мм от первого препятствия, при начальном давлении 155 Торр. Как видно из рисунка, пламя проникает через оба препятствия, хотя, если мы в эксперименте используем в качестве первого плоское препятствие с единственным центральным отверстием 15 мм в диаметре вместо препятствия с двумя отверстиями, пламя через это сложное препятствие не проникнет. Это означает, что предварительная турбулизация пламени первым препятствием в условиях рис. 5 обеспечивает проникновение пламени через второе препятствие.
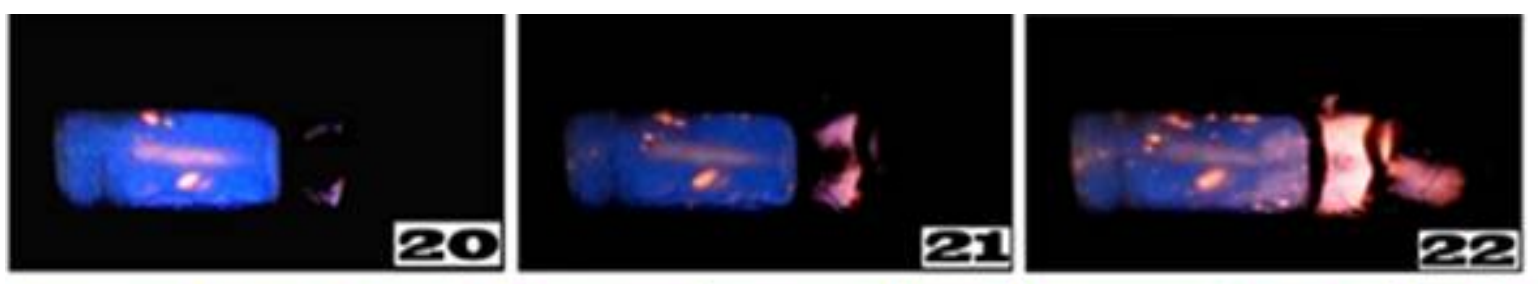

a
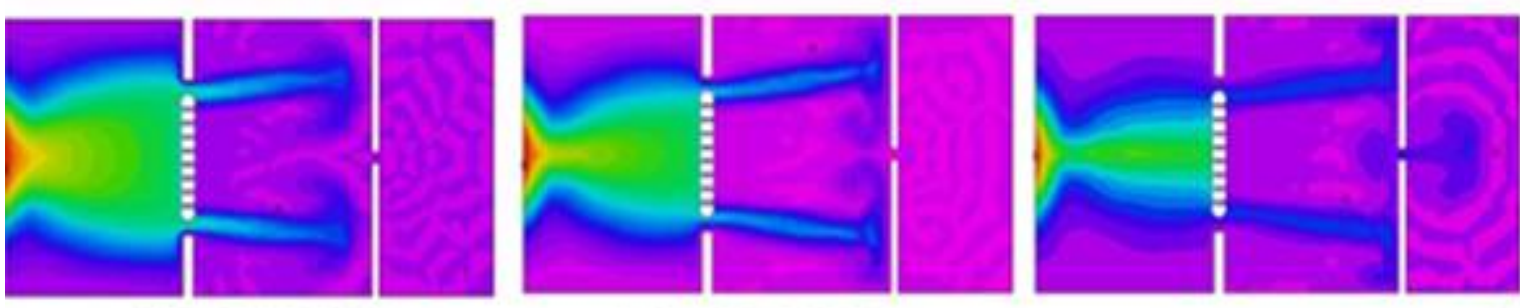

6
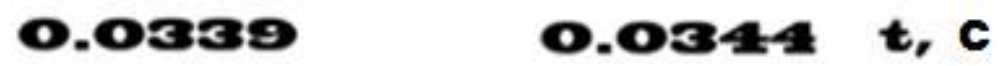

Рис. 5. Скоростная съемка распространения ФП через сложное препятствие, содержащее: a) плоское препятствие диаметром 14 см с двумя симметрично расположенными по оси отверстиями диаметром 15 мм (как на рис. 2) и второе плоское препятствие с одиночным отверстием диаметром 15 мм расположенным в 90 мм от первого препятствия. Начальное давление 155 Торр; б) результаты расчёта процесса распространения пламени через препятствие: изменение безразмерной концентрации начального вещества для $n=0$ на препятствии (граничное условие первого рода)

\section{4. Выводы}

В работе проведено экспериментальное моделирование преграды, которое в случае опасности опыта в масштабе 1:1 необходимо осуществлять. Моделирование в малых объёмах при сравнительно низких давлениях является обязательным для прогнозирования ожидаемых в большом масштабе эффектов [15]. Анализируемое препятствие моделирует, например, блок открытых вентилей в трубопроводе. Из полученных в данной работе результатов можно заключить, что натурный эксперимент в большем масштабе и при атмосферном давлении представляет опасность для целостности установки и для жизни персонала, т.е. его проведение нецелесообразно.

Экспериментально установлено, что максимальное давление и максимальная акустическая интенсивность намного больше для препятствий с двумя и тремя отверстиями, чем с одним центральным отверстием. Установлено, что как минимальное давление проникновения пламени, так и минимальный диаметр отверстия, через которое может проникнуть разбавленное метано-кислородное пламя при начальных давлениях до 200 Торр, уменьшаются с увеличением количества отверстий. Расчёты, проведённые на основе уравнений Навье-Стокса для сжимаемой реагирующей среды в приближении малого числа Маха показали хорошее качественное согласие с результатами экспериментов. Приведённые результаты позволяют прийти 
к выводу, что при оценке пожарной безопасности помещения с несколькими отверстиями величину минимального размера единственного отверстия использовать не следует, потому что при увеличении количества отверстий размер отверстия, достаточный для проникновения пламени, уменьшается.

\section{Литература}

1. Gerlach C., Eder AJordan., M., Ardey N., Mayinger F. Advances in Understanding of Flame Acceleration for the Improving of Combustion Efficiency. In: Kakaç S., Bergles A.E., Mayinger F., Yüncü H. (eds) Heat Transfer Enhancement of Heat Exchangers. Nato ASI Series (Series E: Applied Sciences), 1999, 355. Springer, Dordrecht.

2. Jordan M., Ardey N. and Mayinger F. Influence of turbulence on the deflagrative flame propagation in learns premixed hydrogen mixtures. Available at: www.td.mw.tum.de/tum-td/de/forschung/pub/CD Mayinger/293.pdf

3. Ibrahim S.S. Masri A.R. and Loss J. Prev. in the Process Ind., 2001, V.14, Pp. 213-218.

4. Hargrave G.K., Jarvis S.J., and Williams T.C. A study of transient flow turbulence generation during flame/wall interactions in explosions, Meas. Sci. Technol., 2002, V.13, Pp. 1036-1088.

5. Gelfand B.E., Silnikov M.V., Medvedev S.P., Khomik S.V. Regimes of Supersonic Combustion: Detonation Waves. In: Thermo-Gas Dynamics of Hydrogen Combustion and Explosion. Shock Wave and High Pressure Phenomena. 2012, Springer, Berlin, Heidelberg.

6. Набоко И.М., Рубцов Н.М., Сеплярский Б.С., Цветков Г.И., Черныш В.И. Взаимодействие сферических пламён водородо-воздушных и метано-воздушных смесей с мелкоячеистыми препятствиями при центральном инициировании горения искровым разрядом//Физико-химическая кинетика в газовой динамике. 2012. Том 13, URL:

http://www.chemphys.edu.ru/pdf/2012-05-30-001.pdf

7. Рубцов Н.М., Виноградов А.Н., Калинин А.П., Родионов А.И., Родионов И.Д., Трошин К.Я., Цветков Г.И., Черныш В.И. Установление газодинамических и кинетических особенностей проникновения метано-кислородных пламён через препятствия путем использования 4D спектроскопии и скоростной киносъёмки//Физико-химическая кинетика в газовой динамике. 2016. Т.17, вып. 4. http://chemphys.edu.ru/issues/2016-17-4/articles/661/

8. Chakraborty S., Mukhopadhyay A., Sen S. International Journal of Thermal Sciences, 2008, V.47, P.84-96.

9. Polezhaev V., Nikitin S. In 16th International Congress on Sound and Vibration, Kraków, Poland, 5-9 July 2009, Pp. 2-10.

10. Nickolai M. Rubtsov, The Modes of Gaseous Combustion, Heat and Mass Transfer, Springer International Publishing Switzerland, 2016, 290 P.

11. nano-poroshki.ru/ru/product/nikel-ni/

12. Lewis B. and Von Elbe G. Combustion, Explosions and Flame in Gases, Academic Press, New York, London, 1987, $566 \mathrm{P}$.

13. Majda A. Equations for Low Mach Number Combustion, Center of Pure and Applied Mathematics, University of California, Berkeley, 1982, PAM-112.

14. Backstrom G. Simple Fields of Physics by Finite Element Analysis, GB Publishing, 2005.

15. Виноградов А.Н., Калинин А.П., Родионов И.Д., Родионов А.И, Родионова И.П., Рубцов Н.М., Черныш В.И., Цветков Г.И., Трошин К.Я. Устройство для дистанционного изучения процессов горения и взрыва с использованием гиперспектрометрии и скоростной фотосъемки. Полезная модель. Патент №158856 от 22.07.2015 Опубликовано 20.01.2016. Бюл. №2 